\title{
The Outbreak of Coronavirus (COVID-19) Plagues the World
}

\begin{abstract}
By Guy Bäckman *
The focus is on the outbreak of covid-19 and the patterns inherent in it as they appear in valid statistics and current research. The approach relies on overall goals and strategies in combating the spread of the virus. The examination is placed within an interdisciplinary frame of reference, particularly social policy and economics. A primary and crucial goal of social policy is to ensure, within prevailing economic frames, equity and social justice in the pursuit of sustainable development. The new coronavirus (COVID-19), which was first detected in December 2019 in Wuhan, China, has been declared a global emergency by the World Health Organization, as the outbreak continues to spread outside China. As of the beginning of October 2020, the number of reported covid-19 cases around the world is about 34 million, and the number of deaths amounts to 860 thousand. The worldwide spread of coronavirus is severely affecting the global economy; millions of the global population are under some form of lockdown. The coronavirus pandemic, experienced as a severe shock, has caused not only economic difficulties but also social suffering and concerns for the infected individuals and their families, relatives and closest acquaintances. Increased concern, in connection with the economic slowdown, have given rise to new policies to combat the spread of the new coronavirus never before seen in humans. The policy actions range from social distancing that allow people to work online at home to the closing of borders. In the new emergency conditions, the values and goal orientations emphasize life and health as fundamental human rights. In addition to increased care provisions, other policy actions, such as relief package designed to ensure economic activities and the welfare and well-being of individuals and families, telemedicine, remote work and smart devices are used to enable visiting other people in order to return to normal. Although science guided by humanistic principles, has provided the knowledge to portray the state of the world and human conditions, the preparedness for combating the coronavirus pandemic and the treatment of people infected with the virus, have been found to vary among nations. Significant access barriers remain, especially in remote areas, including the cost of data as well as lack of understanding of foreign languages to manipulate devices and understand internet content. International responsibility and solidarity appear as primary guiding principles in connecting all policy actions to combat coronavirus.
\end{abstract}

Keywords: Advanced technology, global economy, relief package, social distancing, access to data, social suffering, solidarity.

*Professor, Åbo Akademi University, Finland. 


\section{The Rapid Outbreak to a Worldwide Pandemic}

The coronavirus, which was first seen in December 2019 in Wuhan, China, has quickly spread around the world. The focus is on the outbreak of covid-19 and the patterns inherent in it as they appear in valid statistics and current research. The approach relies on overall goals and strategies in combating the spread of the virus (WHO 2020, Armstrong et al. 2020). This examination is placed within an interdisciplinary frame of reference, particularly social policy and economics. A primary and crucial goal of social policy is to ensure, within prevailing economic frames, equity and social justice in the pursuit of sustainable development. Economics in hard times depend on social policy measures for new development (Banerjee and Duflo 2019, Sen 2010).

As of the beginning of October 2020, the number of confirmed covid-19 cases around the world is about 34 million, and the number of deaths amounts to 1 million, and according to statistics from Johns Hopkins University, US, the number of confirmed cases is increasing all the time. The World Health Organization (WHO) on March 11, 2020 declared covid-19 a pandemic, pointing to the rapidly increasing cases of coronavirus infections around the world and the sustained risk of further global spread (Worldometer 2020). The worldwide spread of coronavirus is severely affecting the global economy; millions of the global population is under some form of lockdown. The International Labor Organization (ILO) further estimates that 25 million jobs could be lost due to the coronavirus (ILO 2020). Coronavirus (covid-19) cases continue to rise rapidly across the African continent (WHO 2020a). In these parts of the world, the structures which characterize life (economic, social political and ecological) are different requiring well-adjusted policy actions. The potential for coronavirus to spread to countries with weaker health systems is a huge concern. Countries in Africa and in Southeast Asia are witnessing increasing fears of escalating coronavirus cases, as also in Russia and Eastern Europe. The outbreak has also reached the Nordic countries, where the total number of confirmed cases is lower than in other parts of Europe. The fight against coronavirus has paralyzed society and the economy. ILOs' most pessimistic scenario is that the observed increase in covid-19 cases worldwide forces to continue restrictions that would slow recovery. The scenario estimates job losses of 340 - 400 thousand (ILO 2020a, 2020b). The outbreak of coronavirus has resulted in directives and recommendations from authorities to people to protect themselves and to reduce the interaction that people have in order to minimize their chances of picking up the virus. Nowadays, society is more than ever immersed in a flow of technological innovations that shape our interactions and mediate our access to goods and services and to other individuals. The development of artificial intelligence, robotics, which in times of globalization and economic and social transformations, has led to analyses of the discontent of globalization (Stiglitz 2018) and to a "globotics upheaval" (Baldwin 2019: 4-5). The Internet of Things (IoT) device market is on the rise. The worldwide number of Internet of Things (IoT) connected devices is projected to increase to 43 billion already by 2023 . With almost 2.5 billion monthly active users in the middle of 2019, Facebook is the biggest social network worldwide. Significant access 
barriers remain, especially in remote areas, including the cost of data as well as illiteracy and lack of understanding of foreign languages to manipulate devices and understand internet content.

Social distancing as an infection control method among actions, ranging from, for example, prohibitions on gathering in larger crowds or crowded spaces to the closing of borders. This also refers to crowded or overcrowded spaces were people are living and functioning (WHO 2020, Papanikos 2020). People are allowed to work from home instead of in the office; schools are closed or switched to online classes, and communication with other people. The authorities are nowadays delivering information electronically. Barriers, however, to get access to data particularly exist in remote and poor areas. Changed circumstances with many restrictions have resulted in uncertainty in the business world; investments are not made or they are postponed. Private consumption is also changing. People have shifted to shopping online instead of visiting crowded places, shopping malls and supermarkets. The demand for health and hygiene products has especially increased, while consumption attracting attention or conspicuous consumption has no priority, i.e. consumption used to indicate economic status and accomplishments (Veblen 1953). Comparisons can be made with earlier presented ideas whether we live in a "joyless" and not in a "joyful" society, where comfort and pleasure clarify how people in different ways are in pursuit of satisfaction and thus happiness and wellness (Scitowsky 1992: 59). In the event that a longer period of restrictions is required to contain covid-19, the damage to the economies would be greater. The council of European Union has adopted recommendations on the gradually lifting of the restrictions of non-essential traveling into EU (European Union 2020). According to forecasts (e.g. OECD 2020: 6), economic activities and global growth will markedly decline in 2020. The outbreak of coronavirus has particularly damaged economic activities and growth in the large economies, China and the US, which are the engine of growth, commanding a majority of the global wealth. The gloomy development has caused further fiscal stress because of already expanded welfare commitments, which will even continue because of demographic shifts (Bäckman 2020: 102).

\section{Policy Actions for Securing Health and Life}

The coronavirus pandemic, experienced as a severe shock, has been a social burden causing not only economic difficulties but also social suffering for people because of stagnation of economic activities and mass layoffs. Recovery of the economy from the corona pandemic has led to much discussion among different experts and also in social media. The crucial issue is that we do not know exactly how the pandemic will play out (Anderson et al. (2020). The main task facing the world right now is stopping the spread of the coronavirus. But even when the global public health crisis is under control and the global supply chain disruptions caused by covid-19 end, many large companies will experience uncertainty because it seems to be difficult to determine when business will return to normal. The idea of social distancing is difficult to realize in populous countries, where a 
huge number of people live in low quality, semi-permanent structures, slums. Concerning the government and scientific directions it is pointed out that social distancing, for example, in India and at the African continent is very challenging (WHO 2020a). The Indian government issued a comprehensive advisory statement on coronavirus (Covid-19) on $16^{\text {th }}$ March 2020, directing states across the country to take social distancing measures as a preventive strategy (Bhatt 2020). Until a vaccine is available, there is a need for actions on a broad front. The science, particularly because of progress in advanced technology and algorithmic solutions increasingly portrays the state of the world and human conditions, and reliable knowledge can be received for policy design. Efforts to develop an effective vaccine for Covid-19 are being made. Although a vaccine has already been tested on animals, an effective vaccine to protect people from coronavirus could be produced within a timeframe of at least a year (Ahmed et al. 2020). People who have recovered from infectious disease like covid-19 are generally left with blood that can be used to fight off a virus. Preparatory findings show the potential of such a blood transfusion (convalescent plasma) to treat patients with novel covid19 (Duan et al. 2020). As the Nobel prize-winning economists, Abhijit V. Banerjee and Esther Duflo, have emphasized, good economics in hard times require actions on a broad front of social policies (2019: 262, 318; see also Mohan 2015: 125). It has been considered important to place social arrangements and opportunities in social policy within the frame of life satisfaction and happiness (Sen 1999, Easterlin 2006). As well as economic sustainability improves the level of living, the environmental justice and sustainability also secure not only public health and public safety, but even welfare and well-being. The developing countries are, however, in an insoluble dilemma, how to achieve and maintain sustainability without international help. Bail-out policies, i.e. financial help to countries in severe crisis and on the cusp of failure, to ensure that measures are done when it is economically necessary and in line with rules of bail-out principles and strategies of a world view based on facts (Rosling 2019).

Health policy and other policy actions to prevent transmission from symptomatic and non-symptomatic cases, are flattening the epidemic curve, changing it to a more normal distribution. The greater the reduction in transmission, the longer and flatter the epidemic curve, with the risk of resurgence because of changed behavior and customs among people or because different policy actions are set up. Through different restrictive policy actions, aiming to protect people, especially those with diseases like cancer, diabetes, heart problems and old people, cancelling large gatherings, restricting travel, increasing remote work and other measures, the epidemic curve can be flattened. Many countries have the implementation of relief packages on their policy agendas to stimulate economic activities and to contribute to the well-being of the labor force. The strategic preparedness and response plan, released by WHO on 3rd February 2020 outlines the public health measures that the international community is prepared to provide to support all countries to make provision for and respond to coronavirus. The document provides guiding principles for strategic policy actions (WHO 2020). In the US, a $\$ 2$ trillion coronavirus relief package has been designed to support the economy. The policy actions on a broad front aim to stop the outbreak 
of coronavirus and get a recovery started. Bias in the models used for calculating the effects of implemented restrictions to address all problems in connection with the outbreak of coronavirus, increases the risk that the policy actions will not work according to the original plans, and a new wave of resurgence will emerge. During a resurgence period, the new curve is reshaped extending rightwards. After strong policy actions, the coronavirus pandemic will probably level off and the curve will flatten into a new shape. The way out from the hard times that the pandemic has caused, can either take a V- or a U-shaped form. After a bottom level is reached, a $\mathrm{V}$-curve indicates successful policy actions and that a recovery process is rapidly beginning. A prolonged period of problems at the bottom of the U-curve continues before an upward slump starts again (OECD 2020, Carlsson-Szlezak et al. 2020).

\section{Advanced Technology in a New Role}

In the new circumstances, social policy and economics are pushing the boundaries further to promote freedom and opportunities, and to find optimal and cost-effective solutions to the choices for maintaining well-being in accordance with prevailing and preferred values. The use of advanced technology is, however, accompanied by risks and tensions for both service providers and users (Wrigth 2020). The advanced technology has already made great progress in the developing and designing of thinking and speaking robots to reduce involuntary loneliness and social isolation among, for example, sick children who cannot take part in school education (Sheffield 2017). The use of robots supplementing, or replacing, for example, therapists and social workers, does not perhaps provide the expected values attached to services in the form of human contact and a confidential relationship (Atkinson 2015: 117, Mohan 2018: 43). This development, mostly good but also bad, supports the decisions concerning social distancing during the continuous outbreak of coronavirus. Remote work as a new working style had been on the increase before the outbreak of coronavirus. During the coronavirus pandemic, people are allowed to work at home. Remote work enables a continuation of economic activities and maintenance of welfare. The progress in the development of artificial intelligence for newer and more advanced applications like emotional communication is entering a new era of computermediated remote touch, where it is possible to exchange expressions of feelings, for example, through hugs. The advanced technology may be ready to provide emotional support and hugs for people who are far removed from each other (Block and Kuchenbecker 2019, Mok 2018). As a result of increased education in techno-sciences, researchers have devoted research capacity to finding solutions to support humans through robot hugs. Information and ideas are spread like neurons in brain cells, contributing to a continuing connectedness to prevent idleness and social isolation (Goertzel 2016: 587, Christian and Griffiths 2016). The importance of remote touch is also emphasized as a tool in therapeutic work, which particularly is actualized in periods of exceptional times. When artificial intelligence is used to identify emotions, it can have negative consequences such as misunderstandings and dissatisfactions (Purdy and Daugherty 2017). As a consequence of the rapid 
and revolutionizing development of advanced technology, telemedicine also referred to as telehealth or e-health will become more common, and information on its potential in care is frequently shared in social media (Goertzel 2016, Cooper and Matsuzak 2020).Telemedicine allows health care professionals to evaluate, diagnose and treat patients in remote locations using telecommunications technology. Telemedicine allows patients in remote locations to access medical expertise quickly, efficiently and without travelling. Thus, telemedicine provides convenience and cost-effective medical care. Telemedicine is fast becoming integrated into the daily operations of hospitals, specialty departments, home health agencies, private physician offices and the homes and workplaces of health care consumers around the world. In the globalized world telemedicine can help match medical care practitioners in the developed world with patients in the developing world, far from hospitals, let alone medical specialists (Cooper and Matsuzak 2020). Smart phone applications for "contact tracing,", i.e. to identify people who by chance are in the same physical place at the same time with a contagious patient, have been developed for use in some countries and are reported to be in further development, especially through the introduction of $5 \mathrm{G}$ networks revolutionizing new effective applications in smart cities (Dave 2020, Weeber 2020). Apple and Google have invested a great deal in launching a series of updates to their smartphone operating systems that will use Bluetooth signals to track potential coronavirus cases. Cybercrime is increasing, and cybercriminals may target data from public services and other institutions, as well as private information. Cybercrime conducted by hackers may paralyze the infrastructure or parts of it. Attacks that damage or put vital functions of society out of action, such as oil and gas, electricity, transportation, telecommunications etc. have serious consequences (Wirtz and Weyerer 2017, Baldwin 2019: 185). Technostress appears when people are forced to deal with streams of information, and computer addiction may exist among heavy users. Marginalization of the non-digital population, i.e., persons not able to adapt to rapid changes, has become apparent (World Economic Forum 2019).

\section{Summary and Further Thoughts}

The focus is on the outbreak of covid-19 and the patterns inherent in it as they appear in valid statistics and current research. The approach relies on overall goals and strategies in combating the spread of the virus. As of the beginning of October 2020 , the number of reported covid-19 cases is about 34 million and the number of deaths is about 1 million around the world. The analysis is placed within an interdisciplinary frame of reference, particularly social policy and economics. A primary and crucial goal of social policy is to ensure, within prevailing economic frames, equity and social justice in the pursuit of sustainable development. The worldwide spread of coronavirus is severely affecting the global economy, millions of the global population are under some form of lockdown. In accordance with the core idea that life and health are fundamental human rights, policy actions have been taken, ranging from social distancing, that allow people to work online 
at home to closing of borders. Private consumption is also changing as people shift to shopping online instead of visiting crowded places. Consumption attracting attention or conspicuous consumption is not given high priority; the demand for health and hygiene products has, however, increased. People equipped with communication devices have possibilities to arrange help in their everyday life, such as having their shopping brought to them.

Electronic communication with people in poor and remote areas is not easy because of lack of computer devices and inability to manage advanced communication.

During the difficult times of the coronavirus pandemic, economic activities are being stimulated by governmental relief packages; for example, the US has announced relief stimulus of $\$ 2$ trillion amid growing coronavirus fears. In times of crises good policies also include, in accordance with prevailing and preferred values, maintaining an adequate level of preparedness and risk management strategies. Based on advanced technology and algorithmic solutions, science increasingly portrays the state of the world and human conditions, and reliable knowledge can be received for policy design. The fast-spreading disease is likely to come to a halt as a V-or U-formed curve depending on how successful all the policy actions for "flattening the coronavirus curve" are. Some countries have, however, started to lift restrictions too early, implying risks for a new wave of coronavirus cases. According to reported plans and decisions from some countries to lift restrictions, the visible signs of the decrease in the severity of the coronavirus pandemic, as measured by death rates, has influenced decisions. The coronavirus death rate, however, takes into account milder cases. These estimates, without enough etiological facts, are therefore crucial to enable countries around the world to best prepare policy actions to curb the global coronavirus pandemic. All countries have not, however, succeeded to stop the outbreak of coronavirus and to protect people and their health.

The advance in technology has contributed to the mitigation of unwarranted economic and social suffering, while the progress has been of great help in planning and decision-making for increasing the effectiveness and optimal performance of policy actions. Technological change is widely regarded as one of the main drivers of long-term economic development, while the technological innovations have had far-reaching effects on people's everyday life. The restrictions, fears and uncertainties have resulted in a changed pattern of contact and relations between people.

The most important result is that a new view of solidarity as a community connectedness and togetherness has emerged. This is also a new way to receive social support in the strenuous circumstances caused by the coronavirus pandemic. There are, however, great differences in access to broadband connections and use of the internet. A digital divide exists between individuals who have access to information and communication and those who lack access. Digital divide is obvious between less economically developed countries and more developed countries. Discrepancies are observed in different socio-economic groups and social-cultural contexts. Ecological issues including waste-related problems and climate change are much in focus and a matter of urgency. Global waste is 
estimated to increase to 3.4 billion tons by 2050 from around 2 billion tons in 2016, the greatest increase is projected to be produced in Asia and sub-Saharan Africa. People who are living near rubbish dumps or searching for things from such places, are endangering their health and well-being. Significant access barriers remain, especially in remote areas, including the cost of data as well as illiteracy and lack of understanding of foreign languages to manipulate devices and understand internet content. The out-break of covid-19 and its consequences have much been discussed in scientific circles, for example, in webinars. The crucial issue is, how to achieve and maintain inclusive growth, i.e. equitable opportunities for the populations.

The economy and the technology are embedded in everything when seeking ways to contribute to sustainable social policy and development. Fiscal stress, due to demographic shifts, has already put pressure on the welfare systems. For the governments this means a challenge to adapt policy design within the economic frames. An aging population, with far-reaching economic and social policy consequences, is increasingly apparent in many industrialized nations across the world. Intergovernmental cooperation facilitates the achievement of policy goals for management of diseases and crises. Social justice, solidarity, and equal values are guiding principles. According to forecasts, the global growth is estimated to be weak in 2020. In the advanced economies it also seems to be difficult to boost the worsened economic activities, reflecting the outbreak of the coronavirus pandemic, as well as worldwide tensions and crises, such as geopolitical tensions and conflicts in trade policy. The coronavirus pandemic has changed the world, and how to respond with policies of "hybrid strategies" to create differentiation in policy actions and to gradually lift restrictions. The European Union has adopted recommendations on the gradually lifting of the restrictions of non-essential traveling into EU. The ability to accept new visions and directions in further policy design of preparedness to meet crises and disastrous diseases is associated with good governance in partnership with all interested parties, both internationally and nationally. Policies oriented towards further development must above all be given high priority because today's decisions will have long-term consequences.

\section{Acknowledgements}

I would like to express my thanks to the reviewers for their relevant comments and suggestions that have improved the manuscript.

\section{References}

Ahmed SF, Quadeer AA, McKay MR (2020) Preliminary Identification of Potential Vaccine Targets for the COVID-19 Coronavirus (SARS-CoV-2) Based on SARSCoV Immunological Studies. Viruses 12(3): 254. https://doi.org/10.3390/v12030254.

Anderson RM,_Heesterbeek H, Klinkenberg D, Hollingsworth TD (2020) How will country-based mitigation measures influence the course of the COVID-19 epidemic? 
www.the lancet.com. Published online March 6, 2020. https://doi.org/10.1016/S01 40-6736(20)30567-5.

Armstrong F, Capon A, McFarlane R (2020) Coronavirus is a wake-up call: War with the environment is leading to pandemics. Retrieved from https://bit.ly/3jgVTgC.

Atkinson AB (2015) Inequality. What Can Be Done? Cambridge, MA: Harvard University Press.

Baldwin R (2019) The Globotics Upheaval. Globalization, Robotics, and the Future of Work. New York: Oxford University Press.

Banerjee A, Duflo E (2019) Good Economics for Hard Times. New York: Allen Lane.

Bhatt S (2020) Social Distancing: Really Not? doi: 10.13140/RG.2.2.13724.03204.

Block AE, Kuchenbecker KJ (2019) Softness, Warmth, and Responsiveness Improve Robot Hugs. International Journal of Social Robotics 11; 49-64. Retrieved from https://bit.ly/3mXxUVQ.

Bäckman G (2020) The Inertia of Changes. In Social Policy on the Cusp. Values, Institutions and Change, 91-113, authored and edited by B. Mohan and G. Bäckman. Hauppauge, NY: Nova Science Publishers.

Carlsson-Szlezak P, Reeves M, Swartz P (2020) What Coronavirus Could Mean for the Global Economy. Harward Business Review, March 03, 2020. Retrieved from https://bit.ly/3ialyVt.

Christian B, Griffiths T (2016) Algorithms to Live By. The Computer Science of Human Decision. New York: Henry Holt and Company.

Cooper J, Matsuzak T (2020) Telemedicine in the time of coronavirus. Retrieved from https://bit.ly/347gH3I.

Dave P (2020) Explainer: How smartphone apps can help 'contact trace' the new coronavirus. Technology News, Reuters. https://reut.rs/2SaueBO.

Duan K, et al (2020) The feasibility of convalescent plasma therapy in severe COVID-19 patients: a pilot study. The BMJ. https://bit.ly/36flyCw.

Easterlin RA (2006) Life cycle happiness and its sources: Intersections of psychology, economics, and demography. Journal of Economic Psychology 27(4): 463-482.

European Union (2020) Lifting of travel restrictions: Council reviews the list of third countries. https://bit.ly/2G1frY1.

Goertzel B (2016) The AGI Revolution: An Inside View of the Rise of Artificial General Intelligence. San Jose, CA: Humanity Press.

International Labour Organization (ILO) (2020) Economic Development. news.un.org.-pu bl.pdf.

International Labour Organization (ILO) (2020a) World Employment and Social Outlook. Trends 2020. https://www.ilo.org.

International Labour Organization (ILO) (2020b) COVID-19 and the world of work: Impact and policy responses. https://bit.ly/3ibd3L5.

Mohan B (2018) The Future of Social Work. Seven pillars of practice. Thousand Oaks, CA: Sage.

Mohan B (2015) Global Frontiers of Social Development in Theory and Practice. Climate, economy and Justice. New York: Palgrave Macmillan.

Mok K (2018) HuggieBot Is a Robot Learning How to Hug Humans. The NewStack. https://bit.ly/2S86Wg1.

Organization for Economic Cooperation and Development (OECD) (2020) Coronavirus: The world economy at risk (OECD Interim Economic Assessment. https://bit.ly/3n2 Kao8.

Papanikos, GT (2020) The Demographics of Covid-19 in the European Union. Athens Journal of Social Sciences 7(4): 279-290. 
Purdy M, and Daugherty P (2017) How AI boosts industry profits and innovation. AI Research, Accenture. https://accntu.re/33a40FU.

Rosling H, with O Rosling, A Rosling Rönnlund (2019) Factfulness: Ten Reasons We're Wrong About the World - and Why Things Are Better Than You Think. London: Holder \& Stoughton.

Scitovsky T (1992) The Joyless Economy. An Inquiry into Human Satisfaction and Consumer Dissatisfaction. New York: Oxford University Press.

Sen A (2010) The Idea of Justice. New York: Penguin Books

Sen A (1999) Development as Freedom. New York: Oxford University Press.

Sheffield H (2017) No Isolation: the robot combatting loneliness in chronically ill children. https://bit.ly/3cFOOn0.

Stiglitz JE (2018) Globalization and its discontents revised. New York: W.W. Norton \& Company.

Veblen T ([1899] 1953) The Theory of the Leisure Class: An Economic Study in the Evolution of Institutions. New York: Macmillan.

Weeber S (2020) Smart Cities, Resilience, and the 5G Revolution: Implications for Social Policy. In Social Policy on the Cusp, 221-241, authored and edited by B. Mohan and G. Bäckman. New York: Nova Science Publishers.

Wirtz BW, Weyerer JC (2017) Cyberterrorism and Cyber Attacks in the Public Sector: How Public Administration Copes with Digital Threats: International Journal of Public Administration: 40 (13). https://bit.ly/3iduN8H.

World Economic Forum (2019) What if we get things right? Visions for 2030. https://bit. ly/3kXXOa9.

World Health Organization (WHO) (2020) COVID-19. Strategy Update. https://www. who.int.

World Health Organization (WHO) (2020a) COVID-19. WHO African Region. External Situation Report 7. https://bit.ly/3n9hTMP.

Worldometer 2020 (2020) COVID-19 Coronavirus Pandemic. https://bit.ly/3488Fr9.

Wright M (2020) Digital Technology. Hauppauge, New York: Nova Science Publishers. 